\title{
Reindeer Culture in the Last Quarter of the Moon
}

\author{
Ying Jiang \\ English Department of Humanities and Social Sciences, Heilongjiang Bayi Agricultural University, Daqing, China \\ Email address: \\ happyying101@163.com

\section{To cite this article:} \\ Ying Jiang. Reindeer Culture in the Last Quarter of the Moon. International Journal of Literature and Arts. Vol. 8, No. 1, 2020 , pp. $30-32$. \\ doi: $10.11648 /$ j.ijla.20200801.15
}

Received: February 10, 2020; Accepted: February 21, 2020; Published: February 28, 2020

\begin{abstract}
The Last Quarter of the Moon is the first novel in China to describe the living conditions of the Ewenki people over a century. As an ancient nomadic hunting nationality, the Ewenkis lived a reindeer-leading life and gradually formed the original ethnic minority culture in the deep mountains and dense forests of the Greater Xing'an Mountains. Reindeer culture is a typical representative of it, which not only reflects the daily production and life of the Ewenki people, forms a unique spiritual culture, but also condenses the sincere emotion of the Ewenki in harmony with nature. This text sorts out contents reflecting the reindeer culture in the work through textual reading. It is divided into daily life, including clothing, food, shelter, and transportation; spiritual life, including religious beliefs and art; and the theme of the work embodied by the reindeer. Finally, this article reveals the cultural connotation of reindeer culture for the Ewenki people, and the novel's deep thinking on the integration of primitive ecological civilization and modern civilization.
\end{abstract}

Keywords: The Last Quarter of the Moon, Reindeer, Culture

\section{Introduction}

Reindeer, also known as horned deer, has a gentle temperament, likes moss and mushrooms, and is suitable for living in cold regions. It is good at walking in deep mountains, dense forests, swamps, and deep snow. It is mainly distributed in the northern Arctic Circum Arctic region, including Eurasia and northern North America and some large islands. In China, the Ewenkis have followed reindeer in the virgin forests of the Greater Xing'an Mountains for a living. It can be said that the history of the Ewenki people is a history of harmonious living with reindeer. The Last Quarter of the Moon describes the history of nearly a century of the Ewenki people from the perspective of "I", showing its dependence on reindeer, its closeness to nature, and its dilemma and persistence in modern civilization.

What is a reindeer culture? Ka Lina described it in detail from the perspective of national culture, involving material production, daily life and spiritual life [1]. Tang Ge divides reindeer culture according to the type and habitat of reindeer: reindeer culture is a culture formed around hunting or grazing reindeer. It has three types: one is the type of reindeer hunting in tundra and forest; the other is the type of reindeer herding in the tundra; and the third is the type of reindeer herding in the forest. The reindeer culture of the Ewenki belongs to the third type [2]. This article thinks that the reindeer culture originated from the survival needs of the nomadic hunting nationality and the adaptation to the living habits of the reindeer and nature. It relies on the reindeer, and gradually forms a rich reindeer culture system in daily life and spiritual level. So, what are the specific manifestations of reindeer culture in The Last Quarter of the Moon? What cultural connotations does the reindeer culture reflect on the Ewenki people? What theme does the novel want to express? These questions will be very helpful for the appreciation of the novel.

\section{Reindeer Culture in Daily Life}

The Last Quarter of the Moon mainly shows the historical process of the entire nationality by narrating the daily life of the small figures, life and death. The reindeer culture emerged in the long-term production and living practice of the Ewenki people, and is fully reflected in their clothing, food, shelter and transportation.

On clothing, "Fur protects against the cold. [3]" The winters being long and cold, the Ewenkis have lived in extremely cold environment. Therefore, animal fur has become a good material for clothing. The reindeer is covered with light but extremely cold-resistant fur. The Ewenkis use reindeer fur to make jackets, boots, and pockets, etc. 
In diet, reindeer milk is a very favorite food of the Ewenkis. "Deer milk is the sweetest spring that flows into our bodies in the morning. [3]" They use reindeer milk for daily drinks, entertain guests, and make cheese in reindeer milk as snacks. Therefore, squeezing reindeer milk has become a daily work for women in Ewenkisk. In addition, part of the living materials of the Ewenki people were obtained through the exchange of animal furs with merchants from the Russian border. Reindeer horns, reindeer tendons, reindeer whip, reindeer blood, and reindeer fetuses are the most valuable medicinal materials that Russian merchants are willing to exchange.

In terms of living, the Ewenkis lived in a "shirangju", "They're easy to construct: you chop down twenty or thirty larch trees, saw the trunks into poles about twice a man's height, peel off the bark, sharpen one end, and gather the poles together with the sharp ends pointing to the sky. The poles are evenly spaced in the soil, like countless dancing legs forming a big circle, and then a covering is wrapped around them to protect against the wind and the cold. [3]" Reindeer fur can also be used as a shelter against wind and cold.

In terms of transportation, the Ewenkis call reindeer a "forest boat." Reindeer can travel long distances in snow, swamps, or woodlands with heavy loads, which is a good helper for hunters. As reindeer feed primarily on fresh moss, they need to migrate frequently. The Ewenkis followed the reindeer here and there. It is conceivable how important the reindeer is in the long and frequent migration. In The Last Quarter of the Moon we often read: "The white Malu King (the reindeer) walked at the very front, followed by the reindeer transporting our fire source, and then the reindeer loaded with our household possessions. The men and able-bodied women normally walked with the herd, riding reindeer only if truly tired. [3]" Usually, "We struck a big tree with a wooden club so the reindeer roaming nearby would realize that a task awaited them. Six or seven reindeer soon returned to camp. [3]" In addition, when the Ewenkis went out for hunting, as long as the prey was placed on the reindeer, it would safely send the prey to the camp alone.

\section{Reindeer Culture in Spiritual Life}

The reindeer plays a fundamental and irreplaceable role in the Ewenkis' daily life. The Ewenkis sum up the reindeer culture in their spiritual life, and richly reflect it in religious belief and art.

Shamanism is one of the important contents in the traditional culture of the Ewenki. It is a religion with many gods on the worship of nature. There is worship of the mountain god, the fire god, the wind god, and the rain god. There is also the animal god, such as the worship of bears and foxes. The bridge between humans and gods is the shaman, who eliminates pain and solves problems for the Ewenkis. In The Last Quarter of the Moon, the shaman recalls the soul for the child, calls for the bear bone stuck in the belly for the tribe, heals the reindeer, and prays rain for the forest. Before doing all these, a reindeer is killed for sacrifice. "When Nihau decided to save Puffball, Valodya had quickly seized a fawn that remained in the camp and sacrificed it to the Malu god. [3]" The Ewenkis believed that the reindeer was a tie between man and god, which can pray to God for safety and healing on behalf of others.

There is another description in the novel, which shows the connection between the reindeer and the gods admired by the Ewenkis. "I" in the novel has longed to see the gods in a deerskin pouch as a child, until one day "I" saw the twelve Spirit Figurines stored inside a deerskin pouch, collectively called "Malu". First among them is "Shewek", our Ancestral Spirit. Shewek likes the sound of drumbeats, so a small deerskin drum has been made for It; and Shewek likes to ride reindeer, so a halter and reins have been given to It.

In addition, there should be a reindeer king in the reindeer herd. The shaman wears it a copper bell. On each relocation road, it only marches "Malu", the god of the Ewenki people, and walks at the front of the team. The reindeer king usually cannot be ridden by others.

In terms of art, rock paintings are mentioned in The Last Quarter of the Moon. The Ewenkis used the dark red soil to sketch reindeer, hunters, hounds and Spirit Drums on the weathered rocks of the cliffs. For the first time, "I" painted an image of a man surrounded by eight reindeers on the rock. The image of this man, born from the heart because of deep missing is a complex of "my" dear father, uncle, and husband. This man is surrounded by reindeers. In the heart of "me", reindeer is a kind of hope, bringing people a sense of security. One of "my" most satisfactory rock paintings is "a Spirit Drum with a fire pattern on one side, and seven reindeer fawns circling the Spirit Drum. The Spirit Drum was the moon, and the seven reindeer surrounding it were the stars that comprise The Big Dipper." This rock painting reflects the inseparability of Shamanism and reindeer in the hearts of the Ewenkis, and also shows the lofty status of the two objects in the hearts of the Ewenkis. In addition, Yiliana, the fourth generation of Ewenki people in The Last Quarter of the Moon, began painting with rock paintings. She called the vivid and mischievous reindeer image she had never seen in daily life a "god reindeer". Xiban, also the fourth generation of Ewenki people, created language and painted reindeer when making birch bark crafts. It can be seen that the Ewenkis' love for reindeer is reflected in the unique art and culture of this ethnic minority.

\section{Reindeer Culture in the Dilemma and Development of the Ewenkis in Modern Society}

With the interdependence of the Ewenkis and the reindeer over the ages, the reindeer culture has been deeply rooted in their hearts. From everyday life, we have seen the love and protection of reindeer by the Ewenkis. They affirmed the spirituality of all things and treat others, animals and the nation with great love and selflessness, and have a deep nostalgia for the original homeland. However, this attachment is difficult to adhere to in the course of modern society. The main conflict is reflected in the different attitudes of outsiders and Ewenkis towards reindeer. 
First, with the development of the Greater Xing'an Mountains in the late 1950s, the quiet life of the Ewenkis and reindeer were broken, and they had to migrate frequently to find moss and hunting-friendly places.

Second, the government has set up settlements for the Ewenkis twice in Uchiriovo and Jiliu Township. When seeking opinions from the Ewenkis, there was disagreement due to reindeer. The Ewenkis worry about "How do reindeer live when they get down the mountain?" The village officials thought, "Animals aren't as picky as human beings. Your reindeer can eat tender branches in the summer, and hay in the winter. They won't starve. These words left us all exasperated. [3]" The Ewenkis always think that reindeer are spiritual and draw natural nutrients. They are their friends and family and should not be mistreated at all.

In addition, the Ewenkis and reindeer have tried to integrate into modern civilization, but the process was difficult. The Ewenkis call the car's exhaust "smelly fart" and believe that walking on the flat roads of the town will make people become a cripple; a row of deer rings blocked by a barbed wire at the foot of the mountain is like a "prison", which limits the reindeer's freedom. Reindeer would rather be hungry and thinner than eat forage and bean cake. All kinds of maladjustments imply their dissatisfaction with their new life. The new way of life did not give the Ewenki people the spiritual reliance, but made them more aware of the beauty of the original homeland.

At the end of the novel, the little white reindeer running towards the mountain is a symbol. This ethnic minority with a history of 3,000 years is gradually dying. The number of reindeer is getting smaller and the living environment of the Ewenki people is getting worse. However, the vaguely returning deer ringtone seems to bring a glimmer of hope to the survival of this minortiy. Here is the persistence of "I" and the return of reindeer to nature.

\section{Conclusion}

National culture is a cultural collection with distinct cultural characteristics formed by a nation undergoing a long historical development. Protecting national culture means protecting the national spirit. Reindeer culture is a bright chapter in the unique culture of the Ewenki. It also adds new connotations to China's colorful national culture. The Last Quarter of the Moon shows the rich reindeer culture from the material culture, spiritual culture of the Ewenki people and the theme of the novel. For the Ewenki people, the reindeer culture means primitive, rich, simple and harmonious, which not only reflects the unique Ewenki national customs, but also reflects the harmonious coexistence of human and nature. The author did not leave the reindeer from beginning to end. Finally, the reindeer's return is a sublimation of the theme, which represents the Ewenki people's persistence in their lifestyle, adherence to national culture and national beliefs. This return contains people's deep emotions on the homeland and deep reflection on the human civilization process.

\section{Acknowledgements}

This work is supported by The Key Research Programs for The Economic and Social Development in Heilongjiang Province in 2019 (Foreign Language Discipline) (No. WY2019023-B).

\section{References}

[1] Ka Lina. On the Reindeer Culture of the Reindeer Ewenkis [J]. Heilongjiang Nationalities Series, 2007 (2): 174-178.

[2] Tang Ge. Reindeer Culture of Ewenki Nationality [J]. Heilongjiang Ethnic Series, 1998 (2): 90-94.

[3] Chi Zijian. The Last Quarter of the Moon [M]. Beijing: People's Literature Publishing House, 2010.

[4] Bai Xueyan, Wang Hui. Analysis of Ewenki National Culture in The Last Quarter of the Moon [J]. Heilongjiang Nationalities Series, 2017 (12): 120-123.

[5] Chi Zijian. Heart is beyond Mountains - Lecture at Bohai University [J]. Contemporary Writers Review, 2006, (4): 35-41.

[6] Chi Zijian, Hu Yinhong. Embarrassment, Sorrow, and Helplessness of the Process of Human Civilization - Talk with Chi Zijian about the New Novel The Last Quarter of the Moon [J]. Art Wide Angle, 2006 (2): 34-35.

[7] Cao Meng. Significance and Framework of the Research on the Literary Communication of Northeast Minorities [J]. Journal of Shenyang Normal University (Social Science Edition), 2012 (9): 6-9.

[8] Cai Zhirong. The Contemporary Value of Folk Culture [J]. Northwest Ethnic Studies, 2012 (2): 208-211.

[9] Dong Qian. On Folk Custom Writing in Chi Zijian's The Last Quarter of the Moon [J]. Journal of Dezhou University, 2011 (2): 60-63.

[10] $\mathrm{Du}$ Yejing. Primitiveism and the Dilemma of Civilization-On The Last Quarter of the Moon [J]. Masterpieces Appreciation, 2018 (8): 130-133.

[11] Guo Xiaoting, Leng Jiping. Research on Folk Culture Background of The Last Quarter of the Moon [J]. Masterpieces Appreciation, 2019 (2): 41-43.

[12] Li Hongxiu. Self-adherence to National History and Hidden Pain in Ethnic Groups: An Appreciation of Chi Zijian's Novel The Last Quarter of the Moon [J]. National Forum, 2007 (4): 30-32.

[13] Li Hongxiu. On The Last Quarter of the Moon [J]. Literary Controversy, 2007 (12): 133-138.

[14] Wu Bing'an. Entering the Symbolic World of Folk Customs - On the Theory of Folk Custom Symbols [J]. Jiangsu Social Sciences, 2000 (3): 39-53.

[15] Wei Liqun. Reindeer Culture of Ewenki Nationality [J]. Heilongjiang Shizhi, 2016 (7): 37-39. 